Editor's Note: These short reviews of a recent paper in the Journal, written exclusively by graduate students or postdoctoral fellows, are intended to mimic the journal clubs that exist in your own departments or institutions. For more information on the format and purpose of the Journal Club, please see http://www.jneurosci.org/misc/ifa_features.shtml.

\title{
The Central Amygdala Joins the Lateral Amygdala in the Fear Memory Party
}

\author{
Stacie S. Miller ${ }^{1 \star}$ and Gonzalo P. Urcelay ${ }^{2 \star}$ \\ ${ }^{1}$ Behavioral Neuroscience Program, Department of Psychology, and ${ }^{2}$ Cognitive and Behavioral Sciences Program, Department of Psychology, State \\ University of New York-Binghamton, Binghamton, New York 13902-6000 \\ Review of Wilensky et al. (http://www.jneurosci.org/cgi/content/full/26/48/12387)
}

Negative emotions and social isolation are at the core of some anxiety disorders. Pavlovian fear conditioning, characterized by associations between an initially neutral stimulus [conditioned stimulus (CS)] and a biologically relevant fearful stimulus such as a footshock [unconditioned stimulus (US)] has been proposed as a model of select anxiety disorders. From a neurobiological perspective, it is widely recognized that the limbic system and the amygdala in particular are involved in the processing of emotional information (both positive and negative). Current models of the amygdala consider that auditory and visual conditioned stimuli reach the basolateral amygdala, where they converge and become associated with the US [the anterior basal, basal, and lateral amygdala all form the basolateral amygdaloid complex (BLA)]. Thus, in this model, the BLA is a storage site for affective information, particularly fearrelated memories (LeDoux, 2000). In contrast, the central nucleus of the amygdala (CE) (located ventral to the BLA) is thought to play the role of an output con-

\footnotetext{
Received Dec. 18, 2006; revised Jan. 15, 2007; accepted Jan. 15, 2007. *S.S.M. and G.P.U. contributed equally to this work.

Correspondence should be addressed to either of the following: StacieS. Miller, Behavioral Neuroscience Program, Department of Psychology, State University of New York-Binghamton, Binghamton, NY 13902-6000, E-mail: smiller9@binghamton.edu; or Gonzalo P. Urcelay, Cognitive and Behavioral Sciences Program, Department of Psychology, State University of New York-Binghamton, Binghamton, NY 13902-6000, E-mail: gurcelay@binghamton.edu.

DOI:10.1523/JNEUROSCI.5460-06.2007

Copyright $\odot 2007$ Society for Neuroscience $\quad$ 0270-6474/07/272151-02\$15.00/0
}

duit, relaying information from the BLA to the output areas. However, a recent study by Wilensky et al. (2006) published in The Journal of Neuroscience suggests that plasticity in the $\mathrm{CE}$ also contributes to the behavioral changes that result from fear conditioning.

The BLA has been implicated in fear acquisition and consolidation, whereas the CE is known mainly for its role in fear expression. To reevaluate this model, Wilensky et al. (2006) temporarily inactivated either the BLA or the CE in rats to study the role of each in the fear circuit (acquisition, consolidation, and expression). Rats were classically conditioned to a tone paired with a mild footshock. Twenty-four hours later, Wilensky et al. measured the duration of freezing in the presence of the tone. To test the relative role of the BLA and CE in fear acquisition, artificial CSF (ACSF) or muscimol (a $\mathrm{GABA}_{\mathrm{A}}$ agonist) was infused into the BLA or CE 5-10 min before conditioning. Inactivation of the BLA or CE significantly impaired conditioned freezing compared with ACSF controls, implying that both areas are necessary for fear acquisition [Wilensky et al., 2006, their Fig. $1 a$ (http:// www.jneurosci.org/cgi/content/full/26/ $48 / 12387 / F 1)]$. In another experiment, muscimol or ACSF was infused into the CE 5-10 min before testing to study the role of the CE on fear expression. Corroborating its conventional role in the fear circuit, inactivation of the CE significantly impaired fear expression [Wilensky et al. (2006), their Fig. 1c (http://www. jneurosci.org/cgi/content/full/26/48/ $12387 / \mathrm{F} 1)]$. Finally, the role of the CE in consolidation was studied by muscimol inactivation and by protein synthesis inhibition (using anisomycin) immediately after training. Posttraining inactivation of the CE had no effect on fear memory consolidation [Wilensky et al. (2006), their Fig. 4 (http://www.jneurosci.org/cgi/content/full/26/48/12387/F4)]. Although anisomycin in the CE had no effect on fear memory consolidation during a shortterm test ( $4 \mathrm{~h}$ after training), when protein synthesis is not necessary, it abolished fear memory during a long-term test ( $24 \mathrm{~h}$ after training), when protein synthesis presumably is necessary [Wilensky et al. (2006), their Fig. 5 (http://www.jneurosci. org/cgi/content/full/26/48/12387/F5)].

Alternative explanations for the results were explored. First, cannula placement was confirmed histologically and only subjects with appropriate nuclei stained were analyzed. Also, findings regarding the $\mathrm{CE}$ were not attributable to diffusion of muscimol into the BLA despite their close proximity. Finally, state-dependent learning (caused by drug administration before conditioning but not testing) and reduced sensitivity to the footshock were ruled out as explanations for the results of the fear acquisition experiment.

In summary, this series of experiments suggests that the CE supports associative learning in conjunction with the BLA. Because the CE is necessary for fear 
expression, previous studies using permanent amygdala lesions complicated the interpretation of the role of the $\mathrm{CE}$ in acquisition or performance. The present studies avoided such a confound by using temporary pharmacological inactivation of the target area. With the use of this technique, the authors were able to separate the role of the $\mathrm{CE}$ during acquisition and during the expression of fear memories, thus showing that the CE is necessary for acquisition of fear memories.

The present results are consistent with evidence suggesting a larger role for the $\mathrm{CE}$ in the storage of memories than previously thought. For example, Samson and Paré (2005) recently observed synaptic long-term potentiation (LTP), a putative mechanism of learning, in the CE after stimulation of the posterior thalamic auditory pathways. LTP in this case was dependent on presynaptic NMDA receptors only, because administration of an NMDA antagonist extracellularly blocked
LTP, but administration intracellularly in the postsynaptic neuron had no effect. Based on similar evidence, Paré et al. (2004) proposed a model in which intercalated GABAergic cells between the BLA and CE play a major role in modulating LTP-like facilitation in the CE. Briefly, this model assumes that both the CE and BLA receive information about the CS and US and support fear memory storage. The critical difference between the two nuclei is that the BLA regulates activity in the CE, which participates not only in storage but also in the expression of fear memories.

The results of Wilensky et al. and the model proposed by Paré et al. (2004) are consistent with data obtained using appetitive tasks, in which the CE mediates motivational associations that underlie preparatory conditioning (Balleine and Killcross, 2006). A future challenge will be to develop models of the amygdala that incorporate behavior related to both pos- itive and negative emotional experiences. Wilensky et al. provide a good foundation for the development of such models. A better understanding of the amygdala circuitry will also assist the development of therapies designed to diminish the suffering of people afflicted with anxiety disorders.

\section{References}

Balleine BW, Killcross S (2006) Parallel incentive processing: an integrated view of amygdala function. Trends Neurosci 29:272-279.

LeDoux JE (2000) Emotion circuits in the brain. Annu Rev Neurosci 23:155-184.

Paré D, Quirk GJ, LeDoux JE (2004) New vistas on amygdala networks in conditioned fear. J Neurophysiol 92:1-9.

Samson RD, Paré D (2005) Activity-dependent synaptic plasticity in the central nucleus of the amygdala. J Neurosci 25:1847-1855.

Wilensky AE, Schafe GE, Kristensen MP, LeDoux JE (2006) Rethinking the fear circuit: the central nucleus of the amygdala is required for the acquisition, consolidation, and expression of pavlovian fear conditioning. J Neurosci 26:12387-12396. 